\title{
Implementing the Risk Identification (RI) and Modified Early Obstetric Warning Signs (MEOWS) tool in district hospitals in Rwanda: a cross-sectional study
}

Eugene Tuyishime ${ }^{1^{*}} \mathbb{D}$, Honorine Ingabire ${ }^{1}$, Jean Paul Mvukiyehe ${ }^{1}$, Marcel Durieux ${ }^{2}$ and Theogene Twagirumugabe ${ }^{1}$

\begin{abstract}
Background: Despite reaching Millennium Development Goal (MDG) 3, the maternal mortality rate (MMR) is still high in Rwanda. Most deaths occur after transfer of patients with obstetric complications from district hospitals (DHs) to referral hospitals; timely detection and management may improve these outcomes. The RI and MEOWS tool has been designed to predict morbidity and decrease delay of transfer. Our study aimed: 1 ) to determine if the use of the RI and MEOWS tool is feasible in DHs in Rwanda and 2) to determine the role of the RI and MEOWS tool in predicting morbidity.
\end{abstract}

Methods: A cross-sectional study enrolled parturient admitted to 4 district hospitals during the study period from April to July 2019. Data was collected on completeness rate (feasibility) to RI and MEOWS tool, and prediction of morbidity (hemorrhage, infection, and pre-eclampsia).

Results: Among $478 \mathrm{RI}$ and MEOWS forms used, 75.9\% forms were fully completed suggesting adequate feasibility. In addition, the RI and MEOWS tool showed to predict morbidity with a sensitivity of $28.9 \%$, a specificity of $93.5 \%$, a PPV of $36.1 \%$, a NPV of $91.1 \%$, an accuracy of $86.2 \%$, and a relative risk of 4.1 (95\% Confidential Interval (Cl), 2.4-7.1). When asked about challenges faced during use of the RI and MEOWS tool, most of the respondents reported that the tool was long, the staff to patient ratio was low, the English language was a barrier, and the printed forms were sometimes unavailable.

Conclusion: The RI and MEOWS tool is a feasible in the DHs of Rwanda. In addition, having moderate or high scores on the RI and MEOWS tool predict morbidity. After consideration of local context, this tool can be considered for scale up to other DHs in Rwanda or other low resources settings.

Trial registration: This is not a clinical trial rather a quality improvement project. It will be registered retrospectively.

Keywords: Risk identification, Modified early obstetric warning signs, Early warning system, Maternal morbidity, Quality improvement, Rwanda

\footnotetext{
* Correspondence: tuyishime36@gmail.com

'Department of Anesthesia, Critical Care and Emergency Medicine, College of Medicine and Health Sciences, University of Rwanda, Kigali, Rwanda

Full list of author information is available at the end of the article
}

(c) The Author(s). 2020 Open Access This article is licensed under a Creative Commons Attribution 4.0 International License, which permits use, sharing, adaptation, distribution and reproduction in any medium or format, as long as you give appropriate credit to the original author(s) and the source, provide a link to the Creative Commons licence, and indicate if changes were made. The images or other third party material in this article are included in the article's Creative Commons licence, unless indicated otherwise in a credit line to the material. If material is not included in the article's Creative Commons licence and your intended use is not permitted by statutory regulation or exceeds the permitted use, you will need to obtain permission directly from the copyright holder. To view a copy of this licence, visit http://creativecommons.org/licenses/by/4.0/ The Creative Commons Public Domain Dedication waiver (http://creativecommons.org/publicdomain/zero/1.0/) applies to the data made available in this article, unless otherwise stated in a credit line to the data. 


\section{Background}

Although Rwanda reached Millennium Development Goal (MDG) 3 (Promote gender equality and empower women), the maternal mortality rate (MMR) in the country is still high. MMR has been reduced from almost 500 per 100,000 live births in 2010 to approximately 200 per 100,000 , but this is still far from the 2030 target of 140 per 100,000 [1].

Globally, $75 \%$ of maternal deaths are caused by the following 5 complications: hemorrhage, infections, preeclampsia and eclampsia, obstructed labor, and abortions [2]. This is similar to the situation of Rwanda where these 5 common causes of maternal mortality in Rwanda have remained the same for the last decade [1]. In 2015, PostPartum Hemorrhage (PPH) and sepsis accounted for $46 \%$ of maternal deaths in Rwanda; more than $70 \%$ of deaths occurred in teaching and district hospitals, and $64 \%$ of deaths occurred during the postpartum period [3].

As in many countries, the hospital system in Rwanda includes District Hospitals (DH, about 40) and central Referral Hospitals (RH, 3). Most maternal deaths occur after transfer of patients with obstetric complications from a $\mathrm{DH}$ to a $\mathrm{RH}$ [3]. This referral system is associated with delays at each level (DH and $\mathrm{RH}$ ). This suggests that early recognition of patients at high risk of complications might allow earlier transfer before the development of complications and speed up the access to care at higher level by minimizing delays through easy situation awareness, communication, and decision making among teams. For example, studies done in Ireland and Zimbabwe reported an improvement in the time interval between trigger and antibiotic administration, and preoperative stabilization of women undergoing caesarean section following the implementation of the Early Warning Signs (EWS) tool [4, 5].

Multiple effective tools exist to identify parturient at risk, and in other countries have been shown to improve outcomes [6-12]. However, these tools have never been tested in Rwanda, where patient populations and structure of healthcare delivery are quite different from the context of the tool validations.

We therefore wished to determine the effectiveness of one comprehensive tool developed to fit the context of DHs of Rwanda, the RI and Modified Early Obstetric Warning Signs (MEOWS) tool (See Tables 1 and 2) [6-12]. This tool is based on the risk factors of hemorrhage and preeclampsia used by [6] in California; the risk factors of sepsis used by NICE in 2015, in UK; and regular assessment of 5 physiologic variables: respiratory rate, pulse rate, blood pressure, temperature and mental state [8].

Our study had as primary objective to determine if the use of the RI and the MEOWS tool is a feasible intervention in the setting of $\mathrm{DH}$ in Rwanda.
Our secondary goals were to test for association between abnormal RI and MEOWS score and presence of morbidity, and to evaluate the participants' experience during the use of the RI and MEOWS tool.

\section{Methods}

Aim

This study aimed to evaluate the feasibility of implementing the risk factors identification and MEOWS tool in the setting of DH in Rwanda.

\section{Setting}

This study was conducted in $4 \mathrm{DH}$ referring to the 2 main $\mathrm{RH}$ in Rwanda: the Centre Hospitalier Universitaire de Kigali (CHUK) and the Centre Hospitalier Universitaire de Butare (CHUB). The DH in the study were at Nyanza, Kabutare, Muhima, and Kibagabaga. They are located within $1 \mathrm{~h}$ drive to the Referral hospitals and have a large number of deliveries (Table 3 ). They were selected to provide representative examples of typical DHs in various parts of the country.

\section{Study design}

This was a cross-sectional study conducted in 4 district hospitals (Table 3) using survey methodology.

To assess our primary objective, we collected data on feasibility (completeness rate) during the use of the RI and MEOWS tool (how often and how completely the tool was actually used). In addition, staff were interviewed about their experience while using the RI and MEOWS tool and ability to incorporate it into their workflow.

To assess our secondary objective, we collected clinical data during the implementation period to test for association between abnormal RI and MEOWS score and presence of morbidity as measured a composite outcome of infection, hemorrhage and pre-eclampsia by calculating the relative risk. Also, in order to evaluate the usefulness of the RI and MEOWS tool, we calculated its sensitivity, specificity, accuracy, positive predictive values, and negative predictive values.

Our patient sample size included all parturient presenting at the hospitals between January 1, 2019 and June 30, 2019.

\section{Intervention}

From January to March 2019, the RI and MEOWS tool was adapted to Rwanda context using a modified Delphi method, where a team of 2 anesthesiologists and 2 senior anesthesia residents developed suggested changes to fit the context of DHs in Rwanda.

The main changes were related to the availability of laboratory tests, the different healthcare providers, and the structure of the Rwandan referral system (Tables 1 and 2). 
Table 1 The Risk identification (RI) and Modified Early Obstetric Warning Score (MEOWS) tool. Risk identification (RI) tool

\begin{tabular}{llll}
\hline Criteria & High risk & Moderate risk & Low risk \\
\hline Hemorrhage & Recognition: & Recognition: & Recognition: \\
& -On admission: & -On admission: & -On admission \\
1. Placenta previa, low lying placenta & 1. Prior cesarean birth(s) or uterine surgery & 1. No previous uterine incision \\
2. Suspected Placenta accreta or percreta & 2. Multiple gestation & 2. Singleton pregnancy \\
3. Hematocrit <30, refusal of transfusion, & 3. $>4$ previous vaginal births & 3. < 4 previous vaginal births \\
AND other risk factors: & 4. Chorioamnionitis & 4. No known bleeding disorder \\
4. Platelets < 100,000 & 5. History of previous PPH & \\
5. Active bleeding (greater than show) & 6. Large uterine fibroids & \\
6. Known coagulopathy & & \\
-Evaluate for development of additional risk & -Evaluate for development of additional risk & -Evaluate for development of additional risk \\
factors in labor and postpartum: & factors in labor and postpartum: & factors in labor and postpartum: \\
- Prolonged 2nd Stage labor & - Prolonged 2nd Stage labor: & - Prolonged 2nd Stage labor \\
- Prolonged oxytocin use & - Prolonged oxytocin use & - Prolonged oxytocin use: \\
- Active bleeding & - Active bleeding & - Active bleeding \\
- Chorioamnionitis & - Magnesium sulfate treatment & -Chorioamnionitis \\
- Magnesium sulfate treatment & & - Magnesium sulfate treatment
\end{tabular}

-1 or more high risk criteria: High risk of -1 or more moderate risk criteria: hemorrhage

Moderate risk of hemorrhage

$\begin{array}{ll}\text { Conclusion } & \text { Response: } \\ & \text {-Consider referral if not in labor } \\ & \text {-If in labor close monitoring, type and screen, } \\ & \text { order } 2 \text { units of blood, delivery }\end{array}$

Preeclampsia/ Recognition: Eclampsia CNS:

Awareness: unresponsive

Headache: Unrelieved headache

Vision: Temporary blindness

CVS:

SBP: $\geq 160$

DBP: $50-89$

HR: $61-110$

Chest pain

RS:

RR: $<10$ or $>30$

GIT:

Nausea and vomiting

Abdominal pain

Renal: u.o in mls: $\leq 30$ (in $2 \mathrm{~h}$ )

Proteinuria:

Not relevant

Platelet: $<50$

ASAT/ALAT: $>70$

Cr: $>1.2$

MgSO4 toxicity: Respiration $<12$

1 or more high risk criteria: High risk of preelampsia/eclampsia

\section{Conclusion Response:}

Immediate evaluation (ABCDE approach)

- Transfer to higher acuity level

- 1:1 staff ratio

- Labetalol/hydralazine in 30 min

- In-person evaluation

- Magnesium sulfate loading or

maintenance infusion

$\mathrm{O} 2$ at $10 \mathrm{~L}$ per rebreather mask

- R/O pulmonary edema

- Chest x-ray

-Safe referral to tertiary center
Response:

-Consider referral if not in labor (clinical

judgment)

-If in labor close monitoring, type and screen, book 2 units of blood, delivery

CNS:

Awareness: •Agitated/confused

- Drowsy

- Difficulty speaking

Headache:

- Mild headache

- Nausea, vomiting

Vision: Blurred or impaired

CVS:

SBP: $140-159$

DBP: $50-89$

HR: $111-129$

Chest pain

RS:

RR: $25-30$

GIT:

Nausea and vomiting

Abdominal pain

Renal: u.o: $30-49$

Proteinuria:

$\cdot>+1, \cdot 300 \mathrm{mg} / 24 \mathrm{~h}$

Platelet: $50-100$

ASAT/ALAT: $>70$

Cr: $0.9-1.1$

MgSO4 toxicity: Depression of patellar reflexes

1 or more moderate risk criteria: Moderate risk of preeclampsia/eclampsia

\section{Response:}

- Notify In charge RN or Midwife

- In-person evaluation

-Anesthesia consult

- Consider magnesium

sulfate

-Supplemental oxygen

- Physician should be made aware of

worsening or new-onset proteinuria

\section{Recognition:}

- Order labs/tests
No moderate or high risk of hemorrhage: Low risk of hemorrhage

Response:

-Standard of care

Recognition:

CNS:

Awareness: Alert/oriented

Headache: None

Vision impairment: None

CVS:

SBP: $100-139$

DBP: $\geq 105$

HR: $>130$

No chest pain

RS:

RR:11-24

GIT:

None

None

Renal: u.o: $\geq 50$

Proteinuria:

Trace

Platelet: $>100$

ASAT/ALAT: $<70$

Cr: $<0.8$

MgSO4 toxicity:

- DTR + 1

- Respiration 16-20

No moderate or high risk criteria: No risk of preeclampsia /eclampsia

Response:

Proceed with protocol for normal pregnancy 
Table 1 The Risk identification (RI) and Modified Early Obstetric Warning Score (MEOWS) tool. Risk identification (RI) tool (Continued)

\begin{tabular}{|c|c|c|c|}
\hline Criteria & High risk & Moderate risk & Low risk \\
\hline \multirow[t]{10}{*}{ Sepsis } & $\begin{array}{l}\text { Recognition for every woman (on } \\
\text { admission): } \\
\text { Risk factors: } \\
\text { 1.gestational diabetes, diabetes or other } \\
\text { comorbidities }\end{array}$ & $\begin{array}{l}\text { Recognition for every woman (on } \\
\text { admission): } \\
\text { Risk factors: } \\
\text { 1.gestational diabetes, diabetes or other } \\
\text { comorbidities }\end{array}$ & $\begin{array}{l}\text { Recognition for every woman (on } \\
\text { admission): } \\
\text { Risk factors: } \\
\text { 1.gestational diabetes, diabetes or other } \\
\text { comorbidities }\end{array}$ \\
\hline & $\begin{array}{l}\text { 2.needed invasive procedure such as } \\
\text { caesarean section, forceps delivery, removal } \\
\text { of retained products of conception within } 6 \\
\text { weeks }\end{array}$ & $\begin{array}{l}\text { 2.needed invasive procedure such as } \\
\text { caesarean section, forceps delivery, removal } \\
\text { of retained products of conception within } 6 \\
\text { weeks }\end{array}$ & $\begin{array}{l}\text { 2.needed invasive procedure such as } \\
\text { caesarean section, forceps delivery, removal } \\
\text { of retained products of conception within } 6 \\
\text { weeks }\end{array}$ \\
\hline & 3.prolonged rupture of membranes & 3.prolonged rupture of membranes & 3.prolonged rupture of membranes \\
\hline & $\begin{array}{l}\text { 4.continued vaginal bleeding or an offensive } \\
\text { vaginal discharge }\end{array}$ & $\begin{array}{l}\text { 4.continued vaginal bleeding or an offensive } \\
\text { vaginal discharge }\end{array}$ & $\begin{array}{l}\text { 4.continued vaginal bleeding or an offensive } \\
\text { vaginal discharge }\end{array}$ \\
\hline & $\begin{array}{l}\text { Diagnosis criteria } \\
\text { 1.CNS: new altered mental state on } \\
\text { examination }\end{array}$ & $\begin{array}{l}\text { Diagnosis criteria } \\
\text { 1.CNS: History of new altered mental state: }\end{array}$ & \multirow{5}{*}{$\begin{array}{l}\text { Diagnosis criteria } \\
\text { No high risk or } \\
\text { moderate risk } \\
\text { criteria met: ------- }\end{array}$} \\
\hline & $\begin{array}{l}\text { 2.RS: RR > 25: ------ } \\
\text { or need of FiO2 > 40\% to keep Sat > 92\%: ---- } \\
\text {--- }\end{array}$ & 2.RS: RR > 21-24: -- & \\
\hline & 3. CVS: SBP < 90 mmHg: ----- or HR > 130: & $\begin{array}{l}\text { 3.CVS: SBP:91-100 mmHg: -----or HR: 100- } \\
\text { 130: --- }\end{array}$ & \\
\hline & $\begin{array}{l}\text { 4.Renal: No urine in } \\
18 \mathrm{~h} \text { : ----- } \\
\text { or if foley catheter } \mathrm{U} . \mathrm{O}<0.5 \mathrm{ml} / \mathrm{kg} / \mathrm{h} \text { : -------- }\end{array}$ & $\begin{array}{l}\text { 4.Renal: No urine in } 12-18 \mathrm{~h}:- \\
\text { or if foley catheter U.O: } 0.5-1 \mathrm{ml} / \mathrm{kg} / \mathrm{h} \text { : -------} \\
\text {--- }\end{array}$ & \\
\hline & $\begin{array}{l}\text { 5.Temperature }>39^{\circ} \mathrm{C} \text { : ------------ } \\
\text { 6.Skin: Mottled appearance, } \\
\text { Cyanosis of skin, lips or tongue, Non- } \\
\text { blanching rash of skin: -------- }\end{array}$ & $\begin{array}{l}\text { 5.Temperature }<36^{\circ} \mathrm{C}: \text {-------- } \\
\text { 6.Skin: Signs of potential } \\
\text { infection, including } \\
\text { redness, swelling or } \\
\text { discharge at surgical site } \\
\text { or breakdown of wound: ------- }\end{array}$ & \\
\hline & $\begin{array}{l}-1 \text { or more high risk criteria: High risk of } \\
\text { sepsis }\end{array}$ & $\begin{array}{l}-1 \text { or more moderate risk criteria: } \\
\text { Moderate risk of sepsis }\end{array}$ & $\begin{array}{l}\text {-no high or moderate risk criteria: Low } \\
\text { risk of sepsis }\end{array}$ \\
\hline \multirow[t]{2}{*}{ Conclusion } & $\begin{array}{l}\text { Response: } \\
\text {-Immediate review by senior clinical decision } \\
\text { maker (ABCDE approach) } \\
\text {-Blood test: } \\
\text {-Blood gas for glucose and lactate. } \\
\text {-Blood culture. } \\
\text {-Full blood count. } \\
\text {-C-reactive protein. } \\
\text {-Urea and electrolytes. } \\
\text {-Creatinine. } \\
\text {-Clotting screen }\end{array}$ & $\begin{array}{l}\text { Response: } \\
\text {-Blood test: } \\
\text {-Blood gas for glucose and lactate. } \\
\text {-Blood culture. } \\
\text {-Full blood count. } \\
\text {-C-reactive protein. } \\
\text { - Urea and electrolytes. } \\
\text {-Creatinine. } \\
\text {-Clotting screen } \\
\text { - Review by senior clinical decision maker } \\
\text { within } 1 \mathrm{~h} \\
\text {-IV antibiotics within } 1 \mathrm{~h} \\
\text { - } 500 \mathrm{ml} \text { bolus every } 15 \text { min, repeat up to } 3 \\
\text { times } \\
\text {-If no definitive condition identified, repeat } \\
\text { structured assessment at least hourly }\end{array}$ & \multirow[t]{2}{*}{$\begin{array}{l}\text { Response: } \\
\text {-Clinical assessment and manage according } \\
\text { to clinical judgement }\end{array}$} \\
\hline & $\begin{array}{l}\text { - MEOWS } \\
\text {-IV antibiotics within } 1 \mathrm{~h} \\
-500 \mathrm{ml} \text { bolus every } 15 \text { min, repeat up to } 3 \\
\text { times, if SBP }<90 \mathrm{mmHg} \text { give adrenaline } 1 \\
\mathrm{mg} / 500 \mathrm{ml} \mathrm{NS} \text { to keep MAP> } 65 \text { or SBP }>90 \\
\text { - Refer to a tertiary hospital }\end{array}$ & $\begin{array}{l}\text { - MEOWS } \\
\text {-Source control within } 6 \mathrm{~h} \text {, if deep infection } \\
\text { refer to a tertiary hospital }\end{array}$ & \\
\hline
\end{tabular}

From March to June 2019, the research team implemented the RI and MEOWS tool (Tables 1 and 2). For each hospital, the research team conducted a 20 min teaching session explaining use of the RI and MEOWS tool to all maternity staff during the regular morning meeting. In addition, a co-investigator (HI) selected one coach per hospital to ensure the availability of printed forms in each patient's file and to provide mentorship to all maternity staff as needed. The coach was also available to support both the staff during the use of RI and MEOWS tool and the data collection team. Furthermore, the research team provided needed remote mentorship to each 
Table 2 The Risk identification (RI) and Modified Early Obstetric Warning Score (MEOWS) tool. Modified Early Obstetric Warning Score (MEOWS) tool

\begin{tabular}{|c|c|c|c|c|c|c|c|}
\hline Score & 3 & 2 & 1 & 0 & 1 & 2 & 3 \\
\hline Temperature & & $<35^{\circ}$. C & & $35-37.4^{\circ} . \mathrm{C}$ & & $37.5-39^{\circ} . \mathrm{C}$ & $>39^{\circ} . \mathrm{C}$ \\
\hline $\begin{array}{l}\text { Systolic * } \\
\text { BP }\end{array}$ & $\leq 70$ & $71-79$ & $81-89$ & 90-139 & 140-149 & 150-159 & $\geq 160$ \\
\hline $\begin{array}{l}\text { Diastolic * } \\
\text { BP }\end{array}$ & & & $\leq 45$ & $46-89$ & $90-99$ & 100-109 & $\geq 110$ \\
\hline Pulse & & $\leq 40$ & $40-50$ & $51-100$ & $101-110$ & $111-129$ & $\geq 130$ \\
\hline $\begin{array}{l}\text { Respiratory } \\
\text { Rate }\end{array}$ & & $\leq 8$ & & $9-14$ & $15-20$ & $21-29$ & $\geq 30$ \\
\hline AVPU & & & & Alert & Responds to Voice & Responds to Pain & Unconscious \\
\hline $\begin{array}{l}\text { Urine output } \\
\mathrm{mLs} / \mathrm{hr}\end{array}$ & $<10$ & $<30$ & & Not Measured & & & \\
\hline
\end{tabular}

If the pulse rate is higher than the systolic blood pressure then score 2 for 'Pulse' MEOWS less or equal to 2: Current plan

MEOWS =3-5: Repeat observations, Senior midwife to review, Medical review

MEOWS high or equal to 6: Inform Coordinator or Senior Midwife, Medical review, Anesthesia review, Referral

coach through regular phone calls and WhatsApp messages.

\section{Statistical analysis and sample size calculation}

Our primary endpoint was the fraction of parturient for which the RI and MEOWS tool was fully completed and number of staff that felt it was acceptable as a tool to include in their workflow. Descriptive statistics were used, we reported frequencies and percentages for categorical data, and mean and standard deviation ranges continuous data.

For the secondary outcomes, we tested for association between abnormal RI and MEOWS score at admission and presence of morbidity at discharge by calculating relative risk for a composite outcome of infection, hemorrhage and pre-eclampsia. All statistical tests, we regarded a value of $p<0.05$ as statistically significant.
Sensitivity, specificity, positive predictive values, and negative predictive values were calculated for the sample. SPSS version 2013 was used for analysis.

As a similar study done in UK had a sample size of 676 [13]. In order to have an adequate sample we recruited patients from 4 district hospitals conducting at least 250 deliveries each month.

\section{Results}

Table 3 describes the capacity (number of staff and deliveries) of the 4 district hospitals selected to be included into our study.

Table 4 describes the completeness of the RI and MEOWS tool. Among 478 forms used, 363 (75.9\%) forms were fully completed, 79 (16.5\%) partially completed, and $36(7.5 \%)$ were not completed at all.

Tables 5 and 6 describe the experience of staff during the use of the RI and MEOWS tool. When asked about

Table 3 Characteristics of the 4 district hospitals involved in the implementation of the RI and MEOWS study

\begin{tabular}{|c|c|c|c|c|}
\hline Criteria & Nyanza & Kabutare & Muhima & Kibagabaga \\
\hline \multicolumn{5}{|l|}{ Number of maternity staff } \\
\hline Midwifes & 13 & 15 & 48 & 46 \\
\hline General practitioners & 9 & 3 & 17 & 19 \\
\hline Non physician anaesthetists & 4 & 5 & 8 & 9 \\
\hline Obstetricians & 1 & 0 & 2 & 2 \\
\hline Paediatricians & 2 & 1 & 4 & 2 \\
\hline \multicolumn{5}{|c|}{ Average number of deliveries per month } \\
\hline Vaginal deliveries & 152 & 163 & 505 & 500 \\
\hline Caesarean sections & 133 & 105 & 178 & 200 \\
\hline Total & 285 & 268 & 683 & 700 \\
\hline
\end{tabular}


their experience during use of the RI and MEOWS tool, most of the respondents reported that the tool was easy or very easy to use (92\%), they were willing to use the tool regularly (90.9\%), the tool had improved awareness of patient safety (91.3\%), and the tool decreased delay in recognition and management of critically ill obstetric patients $(86.4 \%)$.

When asked about challenges faced during use of the RI and MEOWS tool, common responses included that the tool was long, it was difficult to use with a low staff

Table 4 Patients' demographics, completeness of the use of the RI and MEOWS tool, and outcome, N: 478

\begin{tabular}{|c|c|}
\hline Variable & Number (\%) \\
\hline Age (Mean, SD) & $28.30,6.38$ \\
\hline Gravida (Mean, SD) & $2.58,1.91$ \\
\hline Parity (Mean, SD) & $1.43,1.67$ \\
\hline ANC (Mean, SD) & $2.83,1.15$ \\
\hline \multicolumn{2}{|l|}{ Married } \\
\hline Yes & $420(89.0)$ \\
\hline No & $52(11.0)$ \\
\hline \multicolumn{2}{|l|}{ Insurance } \\
\hline Yes & $450(95.1)$ \\
\hline No & $23(4.9)$ \\
\hline \multicolumn{2}{|l|}{ Social category } \\
\hline 1 & $37(15.7)$ \\
\hline 2 & $82(34.9)$ \\
\hline 3 & $115(48.9)$ \\
\hline 4 & $1(0.4)$ \\
\hline \multicolumn{2}{|l|}{ District hospital } \\
\hline Kibagabaga & $135(28.2)$ \\
\hline Muhima & $136(28.5)$ \\
\hline Kabutare & $139(29.1)$ \\
\hline Nyanza & 65 (13.6) \\
\hline \multicolumn{2}{|l|}{ Tool use } \\
\hline Completed & $363(75.9)$ \\
\hline Partially completed & $79(16.5)$ \\
\hline Not completed & $36(7.5)$ \\
\hline \multicolumn{2}{|l|}{ Morbidity } \\
\hline Yes & 49 (10.3) \\
\hline No & $429(89.7)$ \\
\hline Length of stay (Mean, SD) & $3.05(2.08)$ \\
\hline \multicolumn{2}{|l|}{ Outcome } \\
\hline Referral & $11(2.3)$ \\
\hline ICU & $7(1.5)$ \\
\hline Reoperation & $2(0.4)$ \\
\hline Care at $\mathrm{DH}$ & $458(95.8)$ \\
\hline
\end{tabular}

Table 5 Respondents' demographics and experience during use of the RI and MEOWS tool. Respondents' demographics

\begin{tabular}{ll}
\hline Demographics & Number (\%) \\
\hline $\begin{array}{l}\text { Hospital name } \\
\text { Kibagabaga }\end{array}$ & $14(56)$ \\
Kabutare & $11(44)$ \\
Profession & \\
Midwife & $23(92)$ \\
Nurse & $2(8)$ \\
Experience & \\
$<1$ & $8(32)$ \\
$2-4$ & $9(36)$ \\
$5-7$ & $6(24)$ \\
$8-10$ & $1(4)$ \\
$>10$ & $1(4)$ \\
\hline
\end{tabular}

to patient ratio, English language was a barrier, and there was unavailability of printed forms.

Tables 7 and 8 describe the capacity of the RI and MEOWS tool to predict morbidity. Among 478 forms within patients' charts, only 399 had complete data on outcomes of interest (RI and MEOWS tool scores and morbidity) and were considered for analysis. The results showed that the RI and MEOWS tool predicts morbidity with a sensitivity of $28.9 \%$, a specificity of $93.5 \%$, a PPV of $36.1 \%$, a NPV of $91.1 \%$, an accuracy of $86.2 \%$, and a relative risk of 4.1 (95\% Confidential Interval (CI), 2.4-7.1).

\section{Discussion}

The completion of the RI and MEOWS tool by $75.9 \%$ of participants suggests an adequate feasibility. Our result was consistent with other previous studies although the level of completeness of our study was not as substantial as in other studies like the study done in UK, Ireland, and Zimbabwe that reported an improvement in the frequency of documentation of vital signs, the time interval between trigger and antibiotic administration, and preoperative stabilization of women undergoing caesarean section following the implementation of the Early Warning Signs (EWS) tool $[4,5,11]$.

In addition, our study found that the abnormal RI and MEOWS tool predicted morbidity $(P<0,0001)$ with a low sensitivity of $28.9 \%$, a high specificity of $93.5 \%$, a high accuracy of $86.2 \%$, a low positive predictive value of $36.1 \%$, and a high negative predictive value of $91.1 \%$.

These findings are similar to most results from other multiple studies conducted in different settings. For example, Singh S et al., [13, 14], did 2 studies implementing the MEOWS with more than 1600 patients in total; the results showed a high sensitivity (89\%) and (86.4\%), 
Table 6 Respondents' demographics and experience during use of the RI and MEOWS tool. Respondents' experience during use of the RI and MEOWS tool

\begin{tabular}{|c|c|c|c|c|}
\hline Questions & Responses & & & \\
\hline $\begin{array}{l}\text { How do you think using the risk factors identification and MEOWS tool } \\
\text { within the existing patient file was? }\end{array}$ & $\begin{array}{l}\text { Very difficult } \\
0(0 \%)\end{array}$ & $\begin{array}{l}\text { Difficult } \\
2(8 \%)\end{array}$ & $\begin{array}{l}\text { Easy } \\
16(64 \%)\end{array}$ & $\begin{array}{l}\text { Very easy } \\
7(28 \%)\end{array}$ \\
\hline $\begin{array}{l}\text { To what extent are you willing to use regularly the Risk identification } \\
\text { and MEOWS tool to your facility? }\end{array}$ & $\begin{array}{l}\text { Very resistant } \\
0(0 \%)\end{array}$ & $\begin{array}{l}\text { Resistant } \\
2(9.1)\end{array}$ & $\begin{array}{l}\text { Willing } \\
9(40.9)\end{array}$ & $\begin{array}{l}\text { Very willing } \\
11(50 \%)\end{array}$ \\
\hline $\begin{array}{l}\text { To what extent do you believe use the risk identification and MEOWS } \\
\text { tool has improved awareness of patient safety at your health care facility? }\end{array}$ & $\begin{array}{l}\text { Not at all } \\
0(0 \%)\end{array}$ & $\begin{array}{l}\text { Somewhat significant } \\
2(8.7 \%)\end{array}$ & $\begin{array}{l}\text { Significant } \\
9(39.1 \%)\end{array}$ & $\begin{array}{l}\text { Very significant } \\
12(52.2 \%)\end{array}$ \\
\hline $\begin{array}{l}\text { To what extent do you believe use of the Risk identification and MEOWS } \\
\text { tool has decreased delay in recognition and management of critically ill } \\
\text { obstetric patients to your facility? }\end{array}$ & $\begin{array}{l}\text { Not at all } \\
0(0 \%)\end{array}$ & $\begin{array}{l}\text { Somewhat significant } \\
3(13.6 \%)\end{array}$ & $\begin{array}{l}\text { Significant } \\
4(18.2 \%)\end{array}$ & $\begin{array}{l}\text { Very significant } \\
15(68.2 \%)\end{array}$ \\
\hline
\end{tabular}

high specificity (79\%) and (85.2\%), an acceptable PPV (39\%) and (53.9\%), and a high NPV (98\%) and (96.9\%) for both studies respectively [13, 14]. The significant difference between our study and the studies done by Singh et al. is a low sensitivity. This can be explained by the fact that, in our context, some patients may develop direct complications of pregnancy like PPH without other risk factors especially when procedures are performed by non-specialists.

When asked about challenges faced during use of the RI and MEOWS tool, most of the respondents reported that the tool was long, the staff to patient ratio was low, the English language was a barrier, and the printed forms were sometimes unavailable. Despite facing these challenges, two essential actions led to a successful implementation of the RI and MEOWS. Those actions include adding the RI and MEOWS tools within patients' charts and nominating one Coach per site to provide regular support to local staff.

There are other challenges to be considered for the successful implementation of the MEOWS tool which have been reported in the literature. These include the lack of multidisciplinary coordination and buy-in, inadequate education about the tool, suboptimal integration within the hospital culture, lack of leadership support, and suboptimal alignment with other quality improvement projects [15-20].

Furthermore, our study found a relative risk of 4.1 (95\% CI, 2.4-7.1) suggesting that having moderate or high scores on the RI and MEOWS increases risk of

Table 7 Comparison of RI and MEOWS tool scores (Moderate/ High versus Low) and Morbidity (Yes versus No), N: 399. Cross tabulation of RI and MEOWS tool scores and Morbidity

\begin{tabular}{lll}
\hline & $\begin{array}{l}\text { Morbidity: } \\
\text { Yes }\end{array}$ & $\begin{array}{l}\text { Morbidity: } \\
\text { No }\end{array}$ \\
\hline RI \& MEOWS level: Moderate or High & 13 & 23 \\
RI \& MEOWS level: Low & 32 & 331 \\
\hline
\end{tabular}

morbidity by 4 fold. This can help timely triaging of high-risk patients with potential to improve outcomes.

Similarly, the implementation of the Obstetric EWS has been found to be effective in predicting severe morbidity, to contribute to improved quality of care, to prevent progressive obstetric morbidity and to improve health outcomes [21]. However, there is limited evidence of the effectiveness of the Obstetric EWS in reducing maternal death across all settings [21].

There are several limitations to consider while interpreting the results of this study. Firstly, our study was conducted in only 4 district hospitals and the results and conclusions may not be applicable to other hospital settings. These hospitals, however, are representative of the country of Rwanda, and the results of this study could be applied to the remaining hospital systems within this country and similar other countries. Secondly, the sample size was small; the study was not powered to determine a difference in mortality.

\section{Conclusion}

The RI and MEOWS tool is a feasible and acceptable in the DHs of Rwanda. In addition, having moderate or high scores on the RI and MEOWS tool predict morbidity. After consideration of local context, this tool can be considered for scale up to the rest of district hospitals of Rwanda or other low resources settings. Further studies are needed to evaluate the impact of the RI and MEOWS tool on maternal mortality in low resources settings.

\section{Abbreviations}

$\mathrm{RI}$ and MEOWS: Risk Identification and Modified Early Obstetric Warning Signs; MMR: Maternal Mortality Rate; MDG: Millennium Development Goal; UK: United Kingdom; MOH: Ministry of health; DH: District Hospital; $\mathrm{RH}$ : Referral Hospital; CEMACH: Confidential Enquiry into Maternal and Child Health; CMQCC: California Maternal Quality Care Collaborative; NICE: National Institute for Health and Care Excellence; CHUK: University Teaching Hospital of Kigali; CHUB: University Teaching Hospital of Butare; SPSS: Statistical Package for the Social Sciences; WFSA: World Federation Society of Anesthesiologists 
Table 8 Comparison of Rl and MEOWS tool scores (Moderate/High versus Low) and Morbidity (Yes versus No), N: 399. The characteristics of the RI and MEOWS tool

\begin{tabular}{lllllll}
\hline $\begin{array}{l}\text { RI \& } \\
\text { MEOWS } \\
\text { level }\end{array}$ & $\begin{array}{l}\text { Chi- } \\
\text { Square } \\
(P \text { value })\end{array}$ & RR $(95 \% \mathrm{Cl})$ & Sensitivity & Specificity & Accuracy & PPV \\
\hline $\begin{array}{l}\text { Moderate } \\
\begin{array}{l}\text { Or High } \\
\text { Low }\end{array}\end{array}$ & $<0.0001$ & $\mathbf{4 . 1}(\mathbf{2 . 4 - 7 . 1 )}$ & $\mathbf{2 8 . 9 \%}$ & $\mathbf{9 3 . 5 \%}$ & $\mathbf{8 6 . 2 \%}$ & $\mathbf{3 6 . 1 \%}$ \\
\hline
\end{tabular}

Morbidity: defined as a composite outcome of PPH, Preeclampsia or Infections, PPV Positive predictive value, NPV Negative Predictive Value

\section{Acknowledgements}

The authors would like to thank Directors of Nyanza, Kabutare, Muhima, and Kibagabaga District Hospitals for supporting the implementation of this project.

\section{Authors' contributions}

$\mathrm{ET}$ and $\mathrm{HI}$ led the study design, protocol development, data analysis and manuscript writing. JPM, TT and MD contributed to study design, protocol development and results interpretation. ET and HI led and supervised data collection and led data cleaning. All authors critically reviewed and approved the final manuscript

\section{Funding}

None.

\section{Availability of data and materials}

The datasets used and/or analyzed during the current study are available from the corresponding author on reasonable request.

\section{Ethics approval and consent to participate}

Ethical approval was obtained from the University of Rwanda College of Medicine and Health Sciences Institutional Review Board (Reference number No 157/CMHS IRB/2019). Written informed consents were obtained from all participants involved in the study.

\section{Consent for publication}

Not applicable.

\section{Competing interests}

The authors declare that they have no competing interests.

\section{Author details}

'Department of Anesthesia, Critical Care and Emergency Medicine, College of Medicine and Health Sciences, University of Rwanda, Kigali, Rwanda.

${ }^{2}$ University of Virginia, Charlottesville, USA.

Received: 16 April 2020 Accepted: 17 August 2020

Published online: 29 September 2020

\section{References}

1. Ministry of Health (MOH). Rwanda Annual Health Statistics. 2015.

2. Hogan D. National, regional, and global levels and trends in maternal mortality between 1990 and 2015 with scenario-based projections to 2030: a systematic analysis by the United Nations Maternal Mortality Estimation Inter-Agency Group. vol. 387, no. 10017; 2017. p. 462-74.

3. Jackson JR, Rulisa SR, Decesare JZ, et al. Maternal Mortality and Near Miss Morbidity at the University Teaching Hospital in Kigali, Rwanda. RMJ. 2015; 72(2).

4. Maguire PJ, O'Higgins AC, Power KA, Daly N, McKeating A, Turner MJ. Maternal bacteremia and the Irish maternity early warning system. Int J Gynecol Obstet. 2015; https://doi.org/10.1016/j.ijgo.2014.11. 022 PMID: 25670063

5. Merriel A, Murove BT, Merriel SWD, Sibanda T, Moyo S, Crofts J. Implementation of a modified obstetric early warning system to improve the quality of obstetric care in Zimbabwe. Int J Gynecol Obstet. 2017; https://doi.org/10.1002/ijgo.12028. PMID: 28099733.
6. Berg CJ, Harper MA, Atkinson SM, et al. Preventability of pregnancyrelated deaths: results of a statewide review. Obstet Gynecol. 2005; 106(6):1228-34

7. National Institute for Health and Care Excellence (NICE) guideline NG51 https://www.nice.org.uk/guidance/ng51, March 2015.

8. Lewis G, editor. The confidential enquiry into maternal and child health (CEMACH) saving mothers' lives: reviewing maternal deaths to make motherhood safer - 2003-2005. The seventh report on confidential enquiries into maternal deaths in the United Kingdom. London: CEMACH; 2007.

9. Lyndon A, Lagrew D, Shields L, Main E, Cape V. Improving Health Care Response to Obstetric Hemorrhage. (California Maternal Quality Care Collaborative (CMQCC) Toolkit to Transform Maternity Care) Developed under contract \#11-10006 with the California Department of Public Health; Maternal, Child and Adolescent Health Division; Published by the California Maternal Quality Care Collaborative. 2013.

10. Maurice L. Druzin, MD; Laurence E. Shields, MD; Nancy L. Peterson, RNC, PNNP, MSN; Valerie Cape, BSBA. Preeclampsia toolkit: improving health care response to preeclampsia (California maternal quality care collaborative toolkit to transform maternity care) developed under contract \#11-10006 with the California Department of Public Health; maternal, child and adolescent health division; Published by the California Maternal Quality Care Collaborative. 2013.

11. Cantwell R, Clutton-Brock T, Cooper G, et al. Saving mothers' lives: reviewing maternal deaths to make motherhood safer: 2006-2008. The eighth report of the confidential enquiries into maternal deaths in the United Kingdom. BJOG. 2011;118(Suppl 1):1-203.

12. Main EK, Cape V, Abreo A, et al. Reduction of severe maternal morbidity from hemorrhage using a state perinatal quality collaborative. Am J Obstet Gynecol. 2017:216:298 e1-11.

13. Singh S, Guleria K, Vaid NB, Jain S. Evaluation of maternal early obstetric warning system (MEOWS chart) as a predictor of obstetric morbidity: a prospective observational study. Eur J Obstet Gynecol Reprod Biol. 2016; https://doi.org/10.1016/j.ejogrb.2016.09.014. PMID: 27792988.

14. Singh S, McGlennan A, England A, Simons R. A validation study of the CEMACH recommended modified early obstetric warning system (MEOWS)*. Anaesthesia. 2012;67:12-1 https://doi.org/10.1111/j.1365-2044. 2011.06896.x. PMID: 22066604.

15. Seiger N, Maconochie I, Oostenbrink R, Moll HA. Validity of different pediatric early warning scores in the emergency department. Pediatrics. 2013:132(04):e841-e85022.

16. Gold DL, Mihalov LK, Cohen DM. Evaluating the pediatric early warning score (PEWS) system for admitted patients in the pediatric emergency department. Acad Emerg Med. 2014;21(11):1249-56.

17. Bokhari SW, Munir T, Memon S, Byrne JL, Russell NH, Beed M. Impact of critical care reconfiguration and track-and-trigger outreach team intervention on outcomes of haematology patients requiring intensive care admission. Ann Hematol. 2010;89(05):505-12.

18. Mhyre JM. D\&Oria R, Hameed AB, et al. The maternal early warning criteria: a proposal from the national partnership for maternal safety. Obstet Gynecol. 2014;124(04):782-6.

19. Knight M, Kenyon S, Brocklehurst P, Neilson J, Shakespeare J, Kurinczuk J (Eds.) on behalf of MBRRACEUK. Saving Lives, Improving Mothers' Care - Lessons learned to inform future maternity care from the UK and Ireland Confidential Enquiries into Maternal Deaths and Morbidity 2009-12. Oxford: National Perinatal Epidemiology Unit, University of Oxford; 2014 
20. Friedman AM, Campbell ML, Kline CR, et al. Implementing obstetric early warning systems. Am J Perinatol Rep. 2018;8:e79-84.

21. Umar A, Ameh CA, Muriithi F, Mathai M. Early warning systems in obstetrics: a systematic literature review. PLoS One. 2019;14(5):e0217864 https://doi. org/10.1371/journal.pone.0217864.

\section{Publisher's Note}

Springer Nature remains neutral with regard to jurisdictional claims in published maps and institutional affiliations.

Ready to submit your research? Choose BMC and benefit from:

- fast, convenient online submission

- thorough peer review by experienced researchers in your field

- rapid publication on acceptance

- support for research data, including large and complex data types

- gold Open Access which fosters wider collaboration and increased citations

- maximum visibility for your research: over $100 \mathrm{M}$ website views per year

At $\mathrm{BMC}$, research is always in progress. 